\title{
PRINCIPLE AND BENEFITS OF THIRD PARTY LOGISTICS APPROACH WHEN MANAGING LOGISTICS SUPPLY CHAIN
}

\author{
Aidas Vasilis Vasiliauskas ${ }^{1}$, Gražvydas Jakubauskas ${ }^{2}$ \\ ${ }^{1}$ Transport Research Institute, Vilnius Gediminas Technical University, Plytinès g. 27, \\ LT-10105 Vilnius, Lithuania.Phone +370 5 2745076. E-mail: aidasv@ti.vgtu.lt \\ ${ }^{2}$ Dept of Transport Management, Vilnius Gediminas Technical University, Plytines g. 27, \\ LT-10105 Vilnius, Lithuania. Phone +370 5274 4780. E-mail: Grazvydas.Jakubauskas@ti.vgtu.lt
}

Received 19 December 2006; accepted 1 February 2007

\begin{abstract}
The principle of third party logistics has grown into a very important and a well-functioning logistics concept, mainly due to outsourcing trends in transport business. Providers of 3PL services complemented the effectiveness of logistics supply chain management extending the performance of hauliers and forwarders to what might be called outsourced logistics services providers. The main driver for this was large transportation companies that have striven to render their limited services to the whole transport chain. Firstly, this extended to what now is called forwarding services, i.e. responsibility and transport service was extended from only physical transportation to additional services. Then some transport and forwarding companies continued enlarging their responsibility so that it included an increased part of the transport chain up to a total responsibility for the entire transportation, from production to consumption. A nature of transportation services became more and more the nature of logistics. Companies started offering complete logistics solutions, instead of only isolated physical transportation services. This allowed a customer to concentrate on the core business instead of paying much attention to material flows.
\end{abstract}

Keywords: 3PL, outsourcing, transportation activities, supply chain management.

\section{Introduction}

International business has been undergoing a period of rapid transformation. Trends towards globalisation, integrated logistics and the development of Information and Communication Technology (ICT) are all reshaping the world's trading patterns and consequently physical trade flows [1,2].

In order to be internationally competitive, businesses are organising strategic worldwide networks that can deliver an efficient and high-quality response to demand from any segment of the world market. The efficient and integrated organisation of such activities is often referred to as global logistics or supply chain management (SCM), and it has become the core of global competitive power.

Logistics has been called the last frontier that even at the present time, the improvement of logistics has been the primary source of companies' to make new profits and maintain competitive advantage. There are also several instances where the logistics system has become the cause of bottlenecks in company's overall management. The potential for reducing total cost and for improving the quality of services provided to customers can be increased through the elimination of these bottlenecks. Also, from the social standpoint, an efficient logistics system could offer possibilities to reduce road congestion and environmental pollution, which could result in increased macroscopic economic productivity [3].

Several innovations have been developed to advance the logistics system. These innovations can be classified broadly into innovations to improve individual processes of logistics, and innovations to improve the logistics system totally. The former includes innovative hardware such as new intermodal terminals with efficient transhipment ability, and innovative software such as truck route planning with ITS (Intelligent Transport Systems) and GPS (Global Positioning System). These piecemeal innovations can be developed to their full abilities only when they are employed into improving bottlenecks.

However, it is unlikely that companies merely have one bottleneck in their business processes. Rather, they have many potential bottlenecks, such that eliminating one bottleneck would usually make another one to emerge. This is why it is necessary to control the business process as a system, and to develop systemmanagement innovations. Among the innovations which have effectively attracted the people's attention are Supply Chain Management (SCM) and Third Party Logistics (3PL) [ 4-6].

This paper focuses on the main principles and functions of 3PL services provider (section 2), exam- 
ines benefits and drawbacks of 3PL concept application (section 3), provides detailed categorization of 3PL services providers (chapter 4) and brings an overview of 3PL market in Europe.

\section{Basic principle and functions of $3 P L$ and multi-actors logistical co-operation}

The concept of 3PL has been developed from the need to extend transportation services by transportation companies to its customers. Basically, 3PL might be defined as outsourcing of transport and logistics activities to outside companies that are neither consignors nor consignees. Usually there is outsourced more than one activity, including storage, warehousing, and transportation. 3PL came into existence during the deregulation of freight transport industry in the 1980s and has progressed in the 1990s along with the development of information technologies $[5,6]$.

The PL Pyramid from 1PL to 5PL might be described as a downstream change of functions in terms of transport/logistics services (Fig 1).

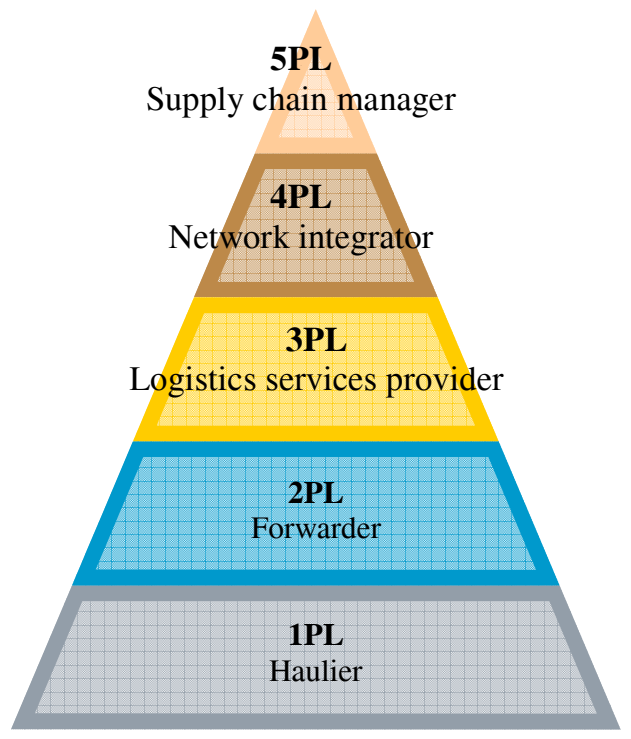

Fig 1. From 1PL to 5PL

Most small businesses buying and selling in the same location are 1PL. As the business expands geographically, the manufacturer's logistics border extends, a 2PL provider is generally a commodity capacity provider, such as a trucking company or a warehouse operator, a 2PL provides service for a single or a small number of functions in the supply chain. They face low returns, with high levels of asset intensity but low barriers of entry.

With the increasing demand for one-stop solutions, many 2PLs have evolved into 3PLs by adding new logistics capabilities and integrating their operations. It may or may not involve asset ownership. 3PL is a broader term that is frequently used to cover businesses in freight forwarding or contract logistics. It performs all or a large portion of a client's supply chain logistics activities and its value adding is based on information and knowledge versus a non differentiated transportations service at the lowest cost. 3PL tends to be asset light with high returns.

The 4PL provider is essentially a logistics integrator or a one-point contact for the manufacturer's logistics outsourcing requirements. They are responsible for contracting various $2 \mathrm{PL}$ and $3 \mathrm{PL}$ providers, and for assembling and managing those end-to-end solutions. The 4PL provider, with its complete overview of the supply chain as well as strong logistics and IT capabilities, can also offer high value added advisory services to the manufacturer.

Most 2PLs companies strive to become 3PLs for higher returns. While 3PLs do own some assets such as key distribution centers in strategic locations or a small trucking fleet to fill emergency needs, they may have outsourced most of their capacity needed by 2PLs. Hence the terms 3PLs focus on logistics solutions and look for the optimal combination of assets available from capacity providers (i.e. 2PLs), 3PLs are less asset intensive.. Their logistics management expertise makes them increasingly counter-cyclical - the worse the cycle, the more companies need to optimize their supply chains. Moreover, the more integrated the service of 3PLs, the closer they are to the customer's operation. This closeness makes 3PLs indispensable to the customer, as the 3PL provider becomes more a partner than a supplier. A customer is more reluctant to change its $3 P L$ provider than a 2 PL $[2,6]$.

The services of 3PL sometimes overlap with the 4PLs. The 4PL segment is more lucrative because these companies charge consulting fees. Currently, 3PL companies are trying to turn themselves into 4PL companies in providing better service satisfaction to their related customers. We can say that 4PL is based on the development of 3PLs and as it is an extension of 3PL, it provides value added service such as planning, information technology integration, transport planning, order tracking and tracing, logistics consulting, application solution, and financial services. But all these functions focus on improving a close linkage with its served customer. From the logistics company to its consigners, as a 3PL company its task is to transport the goods from consigner to consignee, and to be a 4PL provider, 3PLs need to find ways to build strong relations between themselves and their customers, with the abovementioned supporting function to reach the highest level of service efficiency i.e., 4PL is integrated logistics management [2, 5-7].

There is also a new approach of logistics concept that might be defined as 5PL. The 5PL solutions focus on providing overall logistics solutions for the entire supply chain. Supply Chain Management (SCM) is the integration of the activities associated with the flow and transformation of goods in the respective logistics networks through improved supply chain relationships based on a common collaborative performance measurement framework for attaining close, collaborative 
and well-coordinated network relationships to achieve a competitive edge.

\section{Benefits and drawbacks of 3PL concept}

One of the advantages of using 3PL results from economies of scale (merits from large truck fleets, warehouses, etc.) and economies of scope, which encourage companies to increase net value by reducing costs. The effects of these economies are obtained depending on the type of 3PL provider (e.g. IT-equipped, marketing-based, non-asset-based (and then flexible), etc.) Competent 3PL providers possess high coordination ability, enabling them to search for reliable partners or sub-contractors, and to manage efficiently the interfirm flow of goods. Such ability can be developed through experiences as a 3PL.

Likewise, by outsourcing logistics activities, companies can save on capital investments, and thus reduce financial risks. Investment in logistics assets, such as physical distribution centers or information networks, usually needs large and lump sum costs, which involves financial risks. Furthermore, the $3 \mathrm{PL}$ providers can spread the risks by outsourcing to sub-contractors.

Although there are several advantages of using 3PL, some drawbacks also exist. It is not easy to establish a reliable and cost-effective partnership between the firm and the 3PL provider. In order to establish reliable partnership, efforts should be made in two stages: 3PL provider selection and contract signing.

Firstly, in the stage of selecting a new 3PL partner, it is important to select the 3PL provider who has the ability to provide better services. If the firms cannot select reliable 3PL providers, they may suffer from economic losses. It is not easy for firms to judge the ability of the 3PL provider during the selection stage owing to the issue of information asymmetry between the firm (principal) and the 3PL provider (agent). To solve this problem, complex selection procedures are necessary to identify their ability. However, the complex selection procedures may involve additional transaction costs.

Secondly, it is important to establish a system to maintain their reliable partnership once the 3PL partner is selected. Information sharing and apparent risk sharing between the parties is always required. Concerning information sharing, it is needless to say that smoother information exchange will result in a more efficient logistics activity. However, related costs may increase if some information essential to the firm has leaked out. Therefore, the commitment of each party in information sharing is required, and a scheme to ensure these commitments has to be prepared. However, this would also involve additional transaction costs.

Constructing a risk sharing scheme between the firm and the 3PL provider is critical in establishing reliable partnerships. Some of the risks involved in using 3PL are demand risk, inventory risk, and financial risk, among others. The questions are on who will take these risks, and how to compensate the risk holders. "Gain sharing" is a popular example of a rewarding scheme in which the 3PL provider holds part of the risks, and then is given incentives based on the increase of the firm's profit. This risk-sharing method is apparently some sort of a division of work between the firm and the 3PL provider. Establishing good risk sharing also involves transaction costs, although the associated costs can be reduced through the cumulative experiences and IT development.

In order to make a decision whether it is useful to outsource its activities the company defines logistics costs. Hence, logistics cost (per item) function is defined by this equation:

$$
L C=H C+M C,
$$

where: $L C$ - logistics cost; $H C$ - holding cost; $M C$ moving cost.

Holding cost is the sum of rent $(R C)$ and inventory $(I C)$ costs:

$$
H C=R C+I C .
$$

Moving cost is the sum of transport $(T C)$ and handling costs $(H C)$ :

$$
M C=T C+H C .
$$

Hence, the logistics cost is defined as the sum of four main variables:

$$
L C=R C+I C+T C+H C .
$$

\section{Categories of 3PL providers}

Some literature sources are describing four categories of 3PL providers:

1) Standard 3PL providers: this is the most basic form of a 3PL provider. They would perform activities such as, pick and pack, warehousing, and distribution (business) - the most basic functions of logistics. For a majority of these firms, the 3PL function is not their main activity.

2) Service developers: this type of 3PL provider will offer their customers advanced value-added services such as: tracking and tracing, cross-docking, specific packaging, or providing a unique security system. A solid IT foundation and a focus on economies of scale and scope will enable this type of 3PL provider to perform these types of tasks.

3) The customer adapters: this type of 3PL provider comes in at the request of the customer and essentially takes over complete control of the company's logistics activities. The 3PL provider improves the logistics dramatically, but do not develop a new service. The customer base for this type of 3PL provider is typically quite small.

4) The customer developers: this is the highest level that a 3PL provider can attain with respect to its processes and activities. This occurs when the 3PL provider integrates itself with the customer and takes over their entire logistics function. These providers will have few customers, but will perform extensive and detailed tasks for them $[5,6,8]$. 


\section{Outlook of European 3PL market}

The practice of outsourcing logistics operations has grown significantly over the past few years.

Continually pressured to improve the efficiency and reliability of their transportation and logistics operations without sending their overheads through the roof, shippers are realising the potential economic advantage of outsourcing their logistics activities.

Outsourcing opens the door to resources not necessarily available in one's own organisation - world-class services, products, processes and technology - without the need to invest in infrastructure.

European industry is currently experiencing a degree of transition, and increasing numbers of shippers are considering the merits of outsourcing one or more of their logistics operations.

According to the results of survey intended to investigate European 3PL market, in total, $42 \%$ of the survey respondents currently outsource their logistics operations to 3PLs [9-11].

Taking into account that an increasing number of shippers are shifting to a non-asset based business model, there are variety of activities that company outsource to the 3PL services providers. According to the results of the same survey, respondents outsource such activities that are presented in Fig 2.

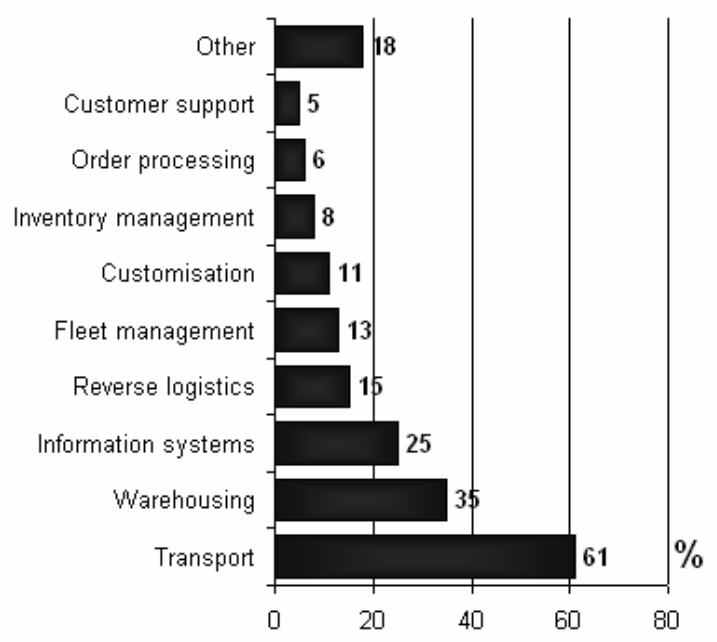

Fig 2. Level of outsourcing logistics functions

The survey confirms that almost two-thirds of the respondents outsource their transportation activities.

Despite the connection between warehousing and inventory management, less than $10 \%$ of the respondents outsource their inventory management, while more than a third happily hand over their warehousing operations to 3PLs. A quarter of the respondents outsource their information systems, indicating increasing confidence in 3PLs' data security levels and their ability to manage the data. However, fleet management is only outsourced by $13 \%$ of the respondents.

The most significant driver for this is the increasing number and complexity of demands by customers. This trend continues to validate the role of the 3PLs in all aspects of logistics. As businesses diversify and their supply chains become increasingly complex and fragile, more and more of them are outsourcing their logistics in order to ensure economical, reliable and efficient deliveries from their suppliers and to their markets.

Competition among 3PLs has become intense. Many have resorted to consolidation so that they can expand their capabilities across sectors and regions. Consolidation may help the larger 3PLs to overcome fragmentation and claim a bigger slice of the market. For smaller companies, consolidation may be crucial to their very survival. Therefore the main challenges for current 3PL services providers seem to be as follows:

- maintaining profits under price pressures from customers;

- relationship with customers (this factor, in combination with the price pressures from customers, points to the considerable sensitivity of 3PLs to the markets they serve).

- globalisation of the 3PL market and delivering services in new geographical regions

- consistently delivering the latest cutting edge technology to customers.

- competing with giant global 3PLs.

- $\quad$ emergence of 4PLs / LLPs.

In relation to opportunities of growth for European 3PL industry the following conclusions can be made: management, technology, management solutions and consultancy were identified as greater growth opportunities than physical services such as freight carriage or warehousing in the 2006 survey.

Providing technology / IT solutions was rated a "good" or "best" opportunity by $77 \%$ of respondents.

Other most promising opportunities were seen to be supply chain consultancy \& design, reverse logistics and global freight management. Areas of growth selected by the fewest respondents were once again packing / picking, general warehousing and freight audit payment.

Of great importance are recognized possibilities of companies to expand geographical boundaries of their activity. According to the results of conducted survey, $37 \%$ of respondents believed China had the most growth potential (more than two-thirds of respondents (70\%) still believe China has either the most "most" or "very good" growth potential).

Also India (56\% of respondents) and Eastern Europe $(65 \%)$ are considered the next most promising regions.

Russia, Brazil and the rest of Asia were all chosen by well over $50 \%$ of respondents for their "good" or "most" growth potential. Apart from Brazil, South America and also North America are generally seen to show little promise of market growth for the 3PLs.

Also when it comes to the question of activity expansion, industry sectors, offering best development opportunities should be identified.

According to the survey, all of the major sectors have at least moderate growth potential. Even the food sector received a rating from $63 \%$ of respondents ranging from average to greatest growth potential. 
$87 \%$ believe the hi-tech / electronics sector has the greatest potential, followed by pharma / medical / healthcare with $82 \%$.

FMCG / CGP with $79 \%$, retail with $77 \%$ and industrial with $77 \%$ are also strongly favoured for their growth potential.

And last but not least is the topic on "how do 3PL clients measure performance of 3PL services providers".

In general, satisfaction levels are generally good. A total of $79 \%$ of the respondents selected "good" (62\%), "higher than expected" $(13 \%)$ or "outstanding" (4\%). In comparison, only $21 \%$ were somewhat less enthusiastic about the performance of their 3PLs.

\section{Conclusions}

1. 3PL allows saving time mainly due to the outsourcing the logistics functions that can free up resources to focus on core competencies of the company instead of secondary ones.

2. 3PL services providers are the experts of logistics business therefore even if the companies have resources available, a company within the supply chain may be able to do it better, simply because of its relative position in the supply chain, supply chain expertise and economies of scale.

3. 3PL companies can share responsibility for managing global supply chains, keeping customers and stores properly stocked, and delivering the perfect order every time.

4. $3 \mathrm{PL}$ is also advantageous when re-engineering distribution networks as the logistics outsourcing can be a quick way to re-engineer distribution networks to meet global market demands and gain a competitive advantage.

5. 3PL performs duties such as quoting, booking, routing, and auditing, but doesn't need to own warehousing facilities, vehicles, or aircrafts. These are often leased on terms equaling those of the 3PL contract minimising liability to capital expenditure.

6. To be useful for the companies, 3PL providers must show their customers a benefit in financial and operational terms by leveraging exceptional expertise and ability in the areas of operations, negotiations, and customer service in a way that complements its customers' pre-existing physical assets.

\section{References}

1. Development of multimodal transport and logistics services. Report by the UNCTAD secretariat. TD/B/COM.3/EM.20/2, 2003

2. BALLOU, R. H. Business logistics management: planning, organizing, and controlling the supply chain (4th edition). New York: Prentice Hall, 1998. 369 p.

3. LAMBERT, D. M.; STOCK, J. R; ELLRAM, L. M. Fundamentals of logistics management. Irwin/McGrawHill. 1998. 611 p.

4. BOWERSOX, D. J.; CLOSS, D. J.; COOPER. M. Supply chain logistics management. USA: Michigan State University, 2001. $656 \mathrm{p}$.

5. SKJOETT-LARSEN, T. Third party logistics - from an inter-organizational point of view. International Journal of Physical Distribution \& Logistics Management, 2000, Vol XXX, No 2, p. 112-127.

6. LUMSDEN, K. Fundamentals of logistics. Gothenburg: Chalmers University of Technology, 2003. 456 p.

7. JARZEMSKIS, A. Determination and evalluation of the factors of outsourcing logistics. Transport, 2006, Vol XXI, No 1, p. 44-47.

8. COYLE, J.; BARDI, E.; NOVACK, R. Transportation. USA: South-Western College Publishing, 1999. 512 p.

9. European 3PL Market Survey Report. 3rd eyefortransport European 3PL Summit 2005. London, UK, 2005.

10. European 3PL Market Report 2006. The European 3PL Market: A brief analysis of eyefortransport's recent survey. 4th eyefortransport European 3PL Summit 2006. Brussels, Belgium, 2006.

11. Outsourcing Logistics Europe 2006: Best practices for managing your 3PL relationships. Amsterdam, Netherlands, 2006. 